\title{
A FORMAÇÃO DA POLÍTICA IMIGRATÓRIA BRASILEIRA: DA COLONIZAÇÃO AO ESTADO NOVO
}

\author{
Ana Luisa Zago de Moraes ${ }^{1}$
}

Resumo: No presente artigo, será estudada a construção da política imigratória no Brasil, desde a relação da imigração com a colonização, passando pela Primeira República, em que houve a relação do imigrante com o anarquista-estrangeiro e, posteriormente, o Estado Novo com o estopim da repressão ao "estrangeiro", não mais "imigrante". Através de uma digressão histórica, objetiva-se a compreensão das origens da política imigratória atual, cuidando-se o presente artigo do início de uma discussão que, futuramente, passará pela Ditadura civil-militar brasileira e pela última transição democrática. Nesse primeiro trabalho, o método utilizado foi a pesquisa bibliográfica, e os resultados iniciais evidenciaram que a política imigratória, outrora relacionada à colonização, objeto de propaganda e interesse governamental devido à necessidade de povoar o imenso território e substituir o trabalho escravo, em períodos autoritários como do Estado Novo se direcionou à repressão do "inimigo externo", como sendo o contraponto da própria formação da nacionalidade brasileira.

Palavras-chave: Brasil. Política. Imigração. Colonização. Formação.

Abstract: In this paper, we will study the construction of immigration policy in
Brazil, since the relationship between immigration and colonization. The First
Republic market the relationship between the immigrant and anarchism abroad
and subsequently the New State was characterized for the repression of the
"foreigner", not "immigrant" anymore. Through a historical digression, we would

1 Mestre e Doutoranda em Ciências Criminais pela PUCRS. Defensora Pública Federal em Porto Alegre. 
like to understand the origins of the current immigration policy. That is just the begging of the discussion, because in the future, we will analyze the Brazilian civil-military dictatorship and the last democratic transition and the Transitional Justice for foreign people. In this first paper, the method used was the literature search, and the initial results show that the immigration policy - except when related to colonization and the interest to populate the vast territory and replace the slave labor - was directed to the suppression of the "external enemy", as the was opposite to the formation of Brazilian nationality, mainly in authoritarian periods us the "New State" or Third Republic..

Keywords: Brazil. Policy. Immigration. Colonization. Formation.

\section{INTRODUÇÃO}

Política migratória é um conjunto de medidas adotadas por determinado Estado para controlar o fluxo de pessoas através de suas fronteiras, bem como a permanência dos estrangeiros. Como o mundo segue ordenado em Estados soberanos, o imigrante é recebido ora como invasor, ora como promotor do desenvolvimento, de acordo com o interesse estatal em cada momento. No entanto, o Estado não se limita ao aspecto negativo de autoridade coatora sobre as pessoas num dado espaço, mas detém outro viés de extrema importância, que é o da proteção e do amparo ao indivíduo (SICILIANO, 2012, p. 5).

$\mathrm{O}$ estrangeiro pode ser observado por diferentes realidades normativas: (a) o imigrante, que é quem que se desloca para outro Estado com o intuito de ali permanecer, legal ou ilegalmente (documentado ou não); (b) o estrangeiro transitório, que vai para outro Estado em caráter temporário; (c) aquele em situação especial, que devido a acordos bilaterais, multilaterais ou regionais possuem os mesmos direitos que os cidadãos nacionais; (d) os refugiados (RAMOS, 2008, p. 721-745).

$\mathrm{Na}$ Europa atual, muito em razão de interesses eleitorais, a migração se tornou bode expiatório da crise econômica, e o trabalhador migrante tem sido acusado de subtrair empregos dos nacionais, abusar dos serviços do Estado e elevar os índices de criminalidade, contrariando as pesquisas a respeito. Ademais, a diversidade racial e cultural gera mal-estar em sociedades descritas como "nostálgicas, homogêneas, individualistas e pautadas pelo consumo" (VENTURA; ILLES, 2013, p. 2). Dessa forma, tem ocorrido um retrocesso do direito humanista desenvolvido no período após a Segunda Guerra Mundial.

Nos Estados Unidos, seguindo a mesma tendência, a demonização do 
estrangeiro atingiu seu ápice após os atentados do 11 de setembro de 2001, quando foi declarada "guerra ao terror" e, junto com isso, guerra aos "forasteiros", principalmente de origem árabe. Nessa "guerra", a descoberta de potenciais terroristas confunde-se com a xenofobia e converte a diferença em ameaça.

O Brasil, por sua vez, é um país caracterizado pela forte miscigenação de seu povo, ocasionada pelo seu passado colonial e pelos significativos fluxos migratórios recebidos durante o período Imperial e, principalmente, Republicano. Ao lado dos Estados Unidos, Canadá e Argentina, o Brasil é um dos países receptores de milhões de europeus e asiáticos que vieram para as Américas em busca de oportunidade de trabalho e ascensão social (BARRACLOUGH, 1983). O período de 1870-1930 marcou o último momento relevante de grande influxo de estrangeiros. Durante esse interregno, o Brasil recebeu cerca de 3,7 milhões de pessoas, inclusive japoneses, sírio-libaneses e judeus. No período subsequente houve significativa redução das imigrações devido à crise de 1929 e ao fechamento das fronteiras decorrente da Constituição de 1934, que estabeleceu cotas para o ingresso de imigrantes (SICILIANO, 2012, p. 9).

Desde então, as restrições ao fluxo migratório se tomaram gradativamente mais rígidas, tanto aqui quanto na Eu- ropa e nos Estados Unidos, especialmente durante o regime militar. Apesar das limitações que foram sendo agravadas durante o século XX, o Brasil, durante mais de quatro séculos, foi marcado pelo intenso fluxo migratório, colaborando para a consolidação da miscigenação supramencionada.

No presente artigo, será estudada a construção da política migratória no Brasil, desde a relação da migração com a colonização, passando pela Primeira República, em que houve a construção do imigrante como anarquista-estrangeiro e, posteriormente, o Estado Novo como o estopim da repressão ao "estrangeiro" (não mais "imigrante", como nos tempos da colonização).

A ideia de "evolução", no presente trabalho, não intenciona organizar a história da repressão ao imigrante de forma linear. Não se trata, portanto, de uma análise historiográfica, de tempo cronológico, uma vez que utiliza também de recursos de memória, de tempo múltiplo, tanto é que não pretende abordar todas as normas direcionadas aos imigrantes, mas apenas aquelas que contribuíram para a construção da atual política imigratória, bem como da política repressiva, em especial o instituto da expulsão. O que se busca, portanto, é resgatar os acontecimentos e textos normativos passados para compreender de onde surgiram as atuais normas que regem a política migratória. 


\section{IMIGRAÇÃO \\ E COLONIZAÇÃO \\ DO BRASIL NO SÉCULO XIX}

Durante quase todo o período que o Brasil ainda era colônia portuguesa e, portanto, desde o "descobrimento" datado de 1500 até a proclamação da independência, em 1822, o território nacional somente conheceu os contingentes estrangeiros desembarcados contra a vontade lusa ou apesar dela, destacando-se os holandeses, os franceses e os ingleses (CÔRTES, 1958, p.8-9).

Entretanto, em 1808, com a vinda da família real portuguesa para o Brasil, foram abertos os portos ao comércio internacional e foi promulgado o decreto que assegurava aos estrangeiros o direito à propriedade territorial, ${ }^{2}$ oportunizando a imigração de contingentes populacionais excedentes do continente europeu. Essa abertura ocorria justamente quando a Europa já era marcada pelo progresso industrial, pela elevada densidade demográfica e pela limitação da disponibilidade de terras (BARRACLOUGH, 1983, p. 64-73). A emigração de orientais, indianos, chineses e japoneses encontra explicação em causas análogas: grandes excessos populacionais, necessitando de espaço para subsistir em melhores condições, dentre outras causas (CÔRTES, 1958, p. 10-11).

Já nessa época, o sistema de colonização - no sentido de habitação e exploração de novas áreas do território nacional - não foi a única forma de fomentar a migração. Algumas correntes migratórias foram eminentemente urbanas, como a portuguesa e a sírio-libanesa, outras para fins de "braço" nas lavouras antes cultivadas por escravos, sem a pretensão de concessão de terras ou exploração de novas áreas. E, muitos dos que se dirigiam às áreas de colonização ou de substituição do trabalho escravo, acabaram por permanecer na cidade, seja pelas condições precárias de vida em algumas colônias, ou simplesmente por desconhecerem o trabalho agrícola (SEYFERTH, 1990, p. 20).

2 Trata-se do Decreto de 25 de novembro de 1808, de D. João VI, cujo objetivo era permitir a concessão de sesmarias aos estrangeiros residentes no Brasil, cujo teor era o seguinte: "Sendo conveniente ao meu real serviço e ao bem publico, aumentar a lavoura e a população, que se acha muito diminuta neste Estado; e por outros motivos que me foram presentes: hei por bem, que aos estrangeiros residentes no Brazil se possamconceder datas de terras por sesmarias pela mesma fórma, com que segundo as minhas reaes ordens se concedem aos meus vassallos, sem embargo de quaesquer leis ou disposições em contrario. A Mesa do Desembargo do Paço o tenha assim entendido e o faça executar. Palacio do Rio de Janeiro em 25 de Novembro de 1808." (BRASIL. Leis etc. Colecção das Leis do Brazil de 1808. Rio de Janeiro: Imprensa Nacional, 1891, p. 166. Disponível em: <http://www.planalto.gov.br/ccivil_03/revista/Rev_48/dim251808. htm>. Acesso em: 24 mar. 2014). 
O núcleo pioneiro de imigrantes foi a colônia de Nova Friburgo, Estado do Rio de Janeiro, fundada em 1818 por imigrantes suíços. Na mesma época, também se estabeleceu uma colônia com imigrantes alemães na Bahia, denominada Leopoldina. Entretanto, houve o fracasso desta e de outras tentativas de ambientação de colonos alemães no Nordeste, e as correntes imigratórias europeias passaram a se dirigir para as regiões Sudeste e Sul do País, sendo que, em 1824 foi fundada a colônia de São Leopoldo, próxima a Porto Alegre, no Rio Grande do Sul (PETRONE, 1982, p. 27).

A intensificação da imigração somente ocorreu após 1850, ano em que foi determinado o fim do tráfico de escravos $^{3}$, e quando a colonização passou para a responsabilidade dos governos provinciais e se abriram oportunidades para a iniciativa privada, porém ainda sujeita à orientação e à fiscalização dos órgãos federais, principalmente ao "Conselho de Imigração e Colonização". Assim, ao lado da colonização oficial, estimulou-se também a atuação das companhias de colonização.

Outro grande impulso à imigração foi a abolição da escravatura em $1888^{4}$, e a necessidade de incentivar a vinda de trabalhadores de fora do país, principalmente para as plantações de café nas grandes fazendas do interior de São Paulo, em substituição ao trabalho escravo (FELMANAS, 1974, p. 18). Em razão disso, foi criado o Departamento de Imigração e Colonização de São Paulo, filiado à Secretaria da Agricultura, com a finalidade de incentivar as Companhias de Imigração, que tinham a concessão de trazer os imigrantes europeus para as lavouras de café, convolando a campanha de imigração para uma campanha de arrecadação de mão de obra.

3 Lei n. ${ }^{\circ}$ 581, de 4 de setembro de 1850 , que estabeleceu medidas para a repressão do tráfico de africanos, em 27 de Setembro de 1850. Disponível em: $<$ http://www.planalto. gov.br/ccivil_03/Leis/LIM/LIM581.htm>. Acesso em: 24 mar. 2014. Não se ignora, ainda, medidas anteriores, porém ineficazes, como a Lei Feijó, promulgada em 7 de novembro de 1831, que também tinha por finalidade principal reprimir o tráfico de africanos. Nesse mesmo ano, também foi promulgada a Lei de Terras que, entre outras coisas, transformou a terra em mercadoria. Regulamentada em 1854 através do Decreto n. ${ }^{\circ} 1318$ de 30 de janeiro, esta Lei aboliu a gratuidade de lotes aos colonos, estabelecendo como único título de posse a compra. Criou a Repartição Geral das Terras Públicas que teria a seu cargo a delimitação, divisão e proteção das terras devolutas e a promoção da colonização nacional e estrangeira. Esta Lei pode ser interpretada como resultado da pressão dos grandes proprietários monocultores de café, que pretendiam drenar a corrente de imigrantes para as suas fazendas (IOTTI, 2010).

4 Lei n. ${ }^{\circ} 3.353$, de 13 de maio de 1888, chamada "Lei Áurea". Disponível em: <http:// www.planalto.gov.br/ccivil_03/Leis/LIM/LIM3353.htm>. Acesso em: 24 mar. 2014. 
A mão de obra imigrante era, portanto, a solução à carência de braços no campo. Era trabalhadora e barata, e passível, segundo parecia aos interessados, de ser paga com os mais baixos salários, em troca somente da sobrevivência: " [...] algo assim, como a escravatura em nova versão, versão século vinte" (FELMANAS, 1974, p. 22). Nessa época, considerava-se que os libertos tinham o vício original de não gostar de trabalhar, o que era uma mácula moral, cuidando-se do "mito da vadiagem, da preguiça natural do brasileiro". Nesse sentido, ao invés de "educar o liberto", decidiu-se pelo que "seria mais econômico, encontrar quem já tivesse a virtude natural" (GUERRA, 2012, p. 31).

A imigração de europeus para o Brasil era objeto de intensa propaganda no Velho Continente, e estimulada não somente por razões econômicas. Isso porque, para muitos intelectuais, políticos e cientistas brasileiros da segunda metade do século XIX e do início do século XX, uma das finalidades da imigração europeia era o "branqueamento da raça” (PETRONE, 1982, p. 38; PRADO JR., 2000, p. 82). Tal intento tinha como base um argumento racista que supunha a superioridade dos brancos e a inferioridade de outras raças, especialmente a negra, e buscava sua legitimidade científica nas teorias raciais em voga na Europa e nos Estados Unidos (SEYFERTH, 1990, p. 20).
A "teoria do branqueamento" pretendia "solucionar" impasse que era a construção de uma nação civilizada apesar de seu povo ser composto de muitos índios, negros e mestiços, e tinha como Oliveira Vianna um dos seus principais idealizadores (VIANNA, 1952, p. 108; CARNEIRO, 1988, p. 90-92). Assim, seria a resposta a esse "problema" do povo brasileiro: após a entrada de grandes contingentes de imigrantes brancos e muita miscigenação, em mais ou menos três ou quatro gerações, a população se tornaria cada vez mais branca, eliminando as raças inferiores e constituindo o utópico "tipo brasileiro". Daí porque a seleção de estrangeiros deveria obedecer a essa demanda de branqueamento (OLIVEIRA, 2006, p. 8 e 25).

Resumidamente, as ideias que persistiam entre esses intelectuais - além de Vianna, influenciaram posteriormente o campo político Francisco Campos, Azevedo Amaral, Gustavo Barroso e Alceu Amoroso Lima, exemplificativamente - e que foram retomadas nos anos 30 podem ser assim enumeradas: (a) admitem a existência de raças superiores e inferiores; (b) delegam às raças manifestações que decorrem de fatores sociais; (c) afirmam a ideia da inferioridade do mestiço; (d) confirmam a influência negativa da presença do sangue negro em todas as civilizações; (e) propõem a formação de uma população eugênica; (f) e a necessidade de contro- 
lar a imigração, incentivando a entrada de elementos arianos (CARNEIRO, 1988, p. 97).

Pelos mesmos motivos, as primeiras campanhas de aliciamento humano ocorreram na Espanha, em Portugal e na Itália - países declaradamente preferidos pelo Estado brasileiro razão do branqueamento da raça, por serem "povos latinos", bem como em virtude dos ideais capitalistas e do afastamento do Oriente (FELMANAS, 1974, p. 20).

Nesse norte, o grande fluxo de imigrantes para o Brasil ocorreu entre 1888 e 1910, coincidindo, portanto, com a extinção do trabalho escravo e com a implantação e consolidação do regime republicano. Trata-se do fenômeno conhecido como "grande imigração". ${ }^{5}$

Durante tal período, foi o Estado de São Paulo que recebeu o maior número de estrangeiros, justamente em razão da necessidade de solucionar o problema de mão de obra nas grandes propriedades cafeeiras. Então, os grandes fazendeiros queriam o imigrante como trabalhador rural, e não como pequeno proprietário, distorcendo a "colonização" em seu sentido nato. Por esse motivo, nessa região, não se constituíram colônias etnicamente homogêneas como no Sul, e a pequena propriedade surgiu apenas na periferia dos grandes latifúndios de café muito depois de iniciado o processo imigratório. E, pela mesma razão, uma parcela considerável dos estrangeiros procurou as áreas urbanas, sobretudo a capital (SEYFERTH, 1990, p. 16-18).

Chegando às fazendas as quais se destinavam, os imigrantes constataram logo que haviam sido ludibriados, e que a nova vida, pela qual haviam optado espontaneamente, os colocava em condições quase de escravidão. Em razão disso, começaram a enviar cartas aos seus conterrâneos, recomendando a não emigrarem da Europa para o Brasil, bem como, principalmente a partir de 1920, começaram maciçamente a fugir para a cidade de São Paulo, à procura de trabalho mais adequado, principalmente na indústria têxtil (FELMANAS, 1974, p. 28). Nesse momento, na Europa, os órgãos oficiais dos países dos emigrados já tomavam medidas no sentido de proibir a continuação da imigração para o Brasil (IOTTI, 2010, p. 7).

No século XIX, os imigrantes, que em sua maioria entraram no Brasil como colonos estrangeiros, isto é, como indivíduos subordinados às

5 Na comemoração dos 500 anos do Brasil, o IBGE apresentou dados oficiais sobre a imigração no Brasil, segundo a nacionalidade, de 1884 a 1939 (período mais extenso que o mencionado como o auge da imigração): 170.645 alemães, 581.718 espanhóis, 1.412.263 italianos, 185.799 japoneses, 1.204 .394 portugueses, 98.962 sírios e turcos, 504.936 outros (OLIVEIRA, 2006, p. 43). 
autoridades governamentais (que, no nível mais imediato, eram os administradores das colônias), não tinham direito à cidadania brasileira. Isso porque a naturalização era quase impossível, principalmente em face dos entraves burocráticos e de uma legislação que sempre foi desfavorável ao imigrante, em qualquer época focalizada. Mesmo aqueles que permaneceram nos grandes centros urbanos também tiveram que enfrentar a burocracia governamental e mais a sua situação de estrangeiros frente a uma população nacional pouco disposta a vê-los como iguais (SEYFERTH, 1990, p. 80).

Naquele século, no entanto, "imigrante" ainda era sinônimo de trabalhador, no sentido de que estavam no país para substituir o "braço escravo" ou para produzir alimentos. A discriminação, porém, já existia, quer em relação à elite econômica e política, que queria "braços" para o trabalho, quer em relação às outras classes sociais, com as quais iam competir no mercado de trabalho das cidades maiores. Um dos efeitos mais importantes dessa situação foi a aglutinação de pessoas da mesma origem (étnica ou regional) em grupos étnicos mais ou menos identificados com valores culturais próprios e reivindicações comuns, como a de alcançar a cidadania plena (SEYFERTH, 1990, p. 81).

Nesse período inicial, estava em vigor a Constituição do Império de $1824,{ }^{6}$ de caráter liberal e proprietista (GAUER, 2014, p. 40-47), que fixou os primeiros critérios para que um indivíduo fosse considerado cidadão brasileiro (art. $6^{\circ}$ ), excluindo os escravos e os estrangeiros, mas conferindo cidadania, dentre outros, aos libertos, aos nascidos no Brasil ainda que de pai estrangeiro (critério do jus solli), aos nascidos no estrangeiro, mas filhos de pai brasileiro, caso venham a residir no Império (jus sanguinis), e aos estrangeiros naturalizados (art. $6^{\circ}$, V). A perda da cidadania, por sua vez, segundo o art. $7^{\circ}$, ocorreria aos banidos por sentença, dentre outros casos, e a suspensão dos direitos políticos "Por Sentença condemnatoria a prisão, ou degredo, emquanto durarem os seus effeitos" (art. $8^{\circ}$, III).

6 "Constituição Política do Império do Brazil", outorgada pelo Imperador D. Pedro I em 25 de março de 1824. Disponível em: <http://www.planalto.gov.br/ccivil_03/constituicao/ constituicao24.htm>. Acesso em: 10 abr. 2014. O documento define, em seu art. 1. ${ }^{\circ}$, o Império como sendo "a associação Politica de todos os Cidadãos Brazileiros". Segundo Ruth Gauer, a escolha de uma solução monárquica em vez de republicana deveu-se à convicção da elite de que só a figura de um rei poderia manter a ordem social, e a questão do Império parece estar ligada à complexidade da sociedade da época vinculada ainda a opções politicas de tradição diferente do modelo republicano (GAUER, 2014, p. 32). 
Um marco importante na luta pela cidadania" foi a "Grande Naturalização" prevista na Constituição republicana de 1891 que, em seu art. 69 definia como brasileiros também os "estrangeiros, que achando-se no Brasil aos 15 de novembro de 1889, não declararem, dentro em seis meses depois de entrar em vigor a Constituição, o ânimo de conservar a nacionalidade de origem", bem como os "estrangeiros que possuírem bens imóveis no Brasil e forem casados com brasileiros ou tiverem filhos brasileiros contanto que residam no Brasil, salvo se manifestarem a intenção de não mudar de nacionalidade" (art. 69, $\S \S 1^{\circ}$ a 5 ). ${ }^{8}$

Em 15 de dezembro de 1889, o Decreto n ${ }^{\circ} 58$-A já previa a "Grande Naturalização", que apenas foi constitu-

7 Importante lembrar que, no início do século XIX, período em que a nação foi imaginada como uma comunidade política, de um estado, as ideias de cidadania que emergiram das Revoluções americana e francesa foram as de cidadão e cidadania em substituição das de "súdito". No entanto, os dois critérios históricos que balizavam o direito à cidadania frente à complexidade de uma sociedade que convivia com indígenas, libertos estrangeiros e nacionais, crioulos e escravos. A hierarquia social impedia a simples inclusão ou exclusão de indivíduos. Entre a racionalidade e o pacto social nasceram novas formas de resoluções, formas essas explicitadas nos discursos dos Constituintes de 1823, que finalizou adotando os critérios já mencionados (GAUER, 2014, p. 47-57).

8 Os tipos de naturalização do período estão explanados no acórdão do Supremo Tribunal Federal relativo ao Recurso Extraordinário nº 9.208 - Min. Relator Orosimbo Nonato - Rio de Janeiro, 26 de dezembro de 1947 (data do julgamento), nominado como “Naturalização tácita - Requisitos constitucionais - Interpretação do art. $69, n .{ }^{\circ} \mathrm{V}$, da Constituição de 1891”. Disponível em: <http://bibliotecadigital.fgv.br/ojs/index.php/ rda/article/viewFile/11322/10285>. Acesso em: 10 abr. 2014. Ainda definindo a amplitude da naturalização tácita e a originária inexigibilidade de formalidades para obtê-la e prová-la: “a) que só manifestação específica em contrário excluiria o interessado dos efeitos da grande naturalização; b) que manifestações posteriores não poderiam alterar o fato consumado, salvo processo de perda de nacionalidade; c) que o título declaratório não poderia ser erigido em solenidade indispensável, mantendo caráter meramente probatório para provar situação já atribuída pela Carta magna; d) que a designação de italiano ainda em documento público não indicaria senão a naturalidade. Assim, nem o desaparecimento de livros, nem a confissão ficta, quando mesmo adequada, podem alterar a resultante de um sistema político que se orientara, sem sombra de dúvida, por uma tendência ampliativa, exatamente oposta à que hoje vigora, após longa experiência e menos romantismo; tampouco se poderia cuidar de aplicação de uma lei de 1938, posterior, aliás, ao falecimento de Picchi” (BRASIL. SUPREMO TRIBUNAL FEDERAL. Recurso Extraordinário n. ${ }^{\circ}$ 5.396, Min. Relator Filadelfo Azevedo. Rio de Janeiro, 25 de outubro de 1943. Disponível em: <http://bibliotecadigital.fgv.br/ojs/index.php/rda/ article/viewFile/9170/8272>. Acesso em: 10 abr. 2014). 
cionalizada em 1891. Tal Decreto previa que seriam também naturalizados aqueles que passassem a residir, a partir da data da publicação normativa, por dois anos, desde que não requeressem expressamente o contrário (art. $2{ }^{\circ}$ ). No art. $3^{\circ}$, estava definida a grande naturalização: "Os estrangeiros naturalizados por este Decreto gozarão de todos os direitos civis e políticos dos cidadãos natos, podendo desempenhar todos os cargos públicos, excepto o de Chefe do Estado".

Cuidou-se de uma medida de facilitação da inclusão nacional dos imigrantes, que já correspondiam a uma parcela significativa da população. Tratou-se, ainda, do reconhecimento da cooperação dos imigrantes no desenvolvimento do território (GUERRA, 2012, p. 43).

\section{O SÉCULO XX:}

DO CONTROLE ESTATAL

E O PARADIGMA DO "ANARQUISTA"

OU "QUANDO O IMIGRANTE SE TORNA ESTRANGEIRO”

Durante o período republicano, mesmo ainda no século XIX, como já dito, iniciou-se um movimento de afirmação da cidadania por parte dos imigrantes, principalmente no aspecto relativo ao direito à participação política. Tal movimento ocorreu por meio da imprensa e outras espécies de propaganda, como forma de garantir os direitos de cidadania até então cerceados. Um dos objetivos era a eleição de representantes "da mesma origem", que pudessem atuar mais objetivamente na defesa dos interesses dos seus grupos étnicos (SEYFERTH, 1990, p. 88).

Em cidades maiores, como São Paulo ${ }^{9}$, no entanto, a reivindicação da cidadania se juntou com outras lutas de cunho trabalhista, por exemplo: os italianos tiveram grande participação nos primórdios da organização sindical no Brasil e nos movimentos sociais, lembrando que eles formavam grande parte do proletariado paulista no início do século. Em muitas levas de imigrantes chegaram operários que haviam tomado parte nas lutas sindicais organizadas na Itália pelos socialistas, e também imigrantes anarquistas, sempre dispostos a tomar parte neste tipo de reivindicação (SEIXAS, 2004, p. 127-154).

Os "anarquistas", no Brasil, eram aqueles que perturbavam a República Velha de diversas formas: criticavam as

\footnotetext{
9 Pelo censo de 1890, a população de São Paulo contava com quase 65 mil habitantes. Destes, 14 mil eram estrangeiros (21\%). Já em 1920, São Paulo tinha quase 580 mil habitantes e destes 206 mil eram estrangeiros, ou seja, mais de um terço $(35,5 \%)$ [BRASIL. Censo Demográfico de 1890. In: GUERRA, 2012, p. 39]. O Deputado Adolpho Gordo, em 1912, calculou "a população do Estado de S. Paulo em 3.600.000 habitantes e o número de estrangeiros em cerca de 1.200.000, ou na terça parte" (GORDO, 1913, p. 39-40).
} 
instituições politicas liberais, a igreja, a família e até a educação tradicional. Cuidavam-se especialmente dos fomentadores de greves, ou seja, pregavam a ação direta mediante a organização dos trabalhadores em movimentos de contestação não mediados pelas instituições formais, que se tornavam um grande incômodo para o governo e para as indústrias (GUERRA, 2012, p. 25; OLIVEIRA, 2006, p. 51).

Dessa forma, considerando que trabalho e ordem pública eram valores centrais na Primeira República, a contestação ao trabalho era inaceitável, fosse com objetivo de alcançar a anarquia, fosse apenas para a recomposição de salários. Tanto é que, nesse período, houve a criminalização da greve pacífica pelo Código Penal de 1890.

A "Grande Naturalização" foi uma resposta a essas lutas e necessidades. Por outro lado, foi um dos estopins para discursos excludentes e de manutenção da ordem vigente. Tais discursos criaram a figura do indesejável, uma espécie de bode expiatório para os problemas da República: o anarquista-estrangeiro. Com este personagem, foi possível associar repressão social com a eficiente medida da expulsão de estrangeiros (GUERRA, 2012, p. 27).

Adolpho Gordo, Deputado Federal na época, foi um dos precursores dessa associação, ao defender, em seus discursos em prol do enrijecimento das normas de expulsão de estrangeiros, que "o Brasil já está se constituindo um refúgio de anarquistas e fomentadores de desordens" (GORDO, 1913, p. 11). Aduzia que, além de fomentadores de greves, na primeira década do século XX eles estavam incitando os colonos "com $o$ intuito de desorganizarem completamente o serviço agrícola, promovendo, durante a colheita, uma greve geral". Defendia, ainda, a extrema facilidade da naturalização, o que atrairia os "indesejáveis", de forma que a facilitação da expulsão e o aumento da repressão seria uma medida de "profilaxia social", uma vez que impediria a invasão do país por "elementos nocivos", perturbadores da "vida normal" (GORDO, 1913, p. 31-32).

Cuida-se de uma estratégia de exclusão sofisticada: a junção do desordeiro com o estrangeiro, criando um discurso do inimigo externo. Se o incômodo for externo, seria possível mandá-lo de volta para fora do País e se livrar do problema, de forma rápida, econômica e eficaz, motivo pelo qual foi nessa época em que se iniciaram os debates na Câmara de Deputados sobre o instituto da expulsão, liderados por Adolpho Gordo, nos termos acima. Então, se nos primeiros anos da República o principal problema era lidar com os escravos libertos, sendo que o imigrante era considerado "detentor natural" da capacidade de trabalho, nos anos seguintes o anarquismo se consolidou como o "inimigo da ordem do trabalho" (GUERRA, 2012, p. 38). 
Acrescente-se que, como a elite e o Estado não admitiam a existência de problemas sociais no Brasil (como o desemprego e a miséria), qualquer movimento contestatório da ordem era visto como algo importado, ou seja, um mal causado pela infiltração do estrangeiro subversivo. Consagrou-se, com isso, o "[...] mito do imigrante militante, que traz da Europa experiência sindical e politica" (BONFÁ, 2009, p. 187).

Essas mudanças ocorreram durante o início da construção do nacionalismo ufanista brasileiro, que posteriormente tomou força durante o Estado Novo. ${ }^{10}$ Esse nacionalismo lutava contra o passado, avaliado negativamente, se contrapondo à colonização e ao Império, e prestigiava a terra e o homem nacional, que falava a língua "brasileira" (OLIVEIRA, 2006, p. 154). Aliás, durante a Primeira República, a definição do brasileiro começou a ser construída por exclusão, em oposição ao estrangeiro, que passava então a encarnar o defeito, um mal que concorria em periculosidade com o próprio "atraso brasileiro", característico do Império, e que não mais poderia persistir em uma sociedade em fase de industrialização e voltada ao progresso (OLIVEIRA, 1990, p. 108, p. 124).

Dessa forma, houve uma alteração conceitual significativa: de imigrantes, passaram a ser estrangeiros. E, enquanto o imigrante pode ser integrado na nova sociedade, inclusive pelo caráter de definitividade que representa a migração e a própria colonização, o estrangeiro será sempre o de fora e não faz parte da nação, tampouco da construção do incipiente nacionalismo. Essa alteração da nomenclatura, aliás, facilitou o trabalho dos parlamentares ao aprovar as leis de expulsão, destinadas justamente aos "estrangeiros", em especial aos "indesejáveis" avaliados sob parâmetros como o de utilidade e nocividade, muito afetos ao positivismo em voga na época (GUERRA, 2012, p. 45-46).

Ao final da República Velha, prevaleceu a orientação de que, envolvendo estrangeiros, a competência é exclusiva

$10 \mathrm{O}$ nacionalismo é uma representação ideológica preocupada em definir os traços específicos de um povo e suas diferenças frente aos demais: identidade e alteridade. Pode ser político ou cultural. O primeiro está preocupado com a construção de Estados-nacionais, e se faz presente em todos os momentos em que se procura reestruturar a vida política de um país. Já o cultural é baseado nos traços que definem a identidade de um povo e o diferenciam dos demais (costumes, etnias, religiões e língua), e esteve presente no romantismo no século XIX e no modernismo dos anos 20, e foi retomado no Estado Novo. A interpretação ufanista do nacionalismo é aquela que dialoga mais com elementos da cultura, com valores de longa duração como a terra e o caráter do ser humano que a habita, e sua interpretação da história da nação é otimista (OLIVEIRA, 1990, p. 143, p. 188-189). 
do Poder Executivo, o responsável pelas questões de soberania. Tratou-se da vitória das orientações repressivas. Em mensagem ao Congresso em 1924, Artur Bernardes explicava:

As leis que regulam a aquisição da nacionalidade precisam ser revistas, com uma orientação mais conservadora, que restrinja o excesso de liberalidade nas naturalizações, com grave prejuízo da ordem pública e inconveniente assimilação de elementos indesejáveis (BONFÁ, 2013).

DO ADVENTO DO ESTADO NOVO AO ÚLTIMO GOLPE MILITAR: NACIONALISMO, AUTORITARISMO E REPRESSÃO AO IMIGRANTE

A Primeira República foi o período que perdurou da proclamação deste regime, em 1889, até 1930 - nesse interregno, mas já no século XX, houve a mudança do paradigma do colono-imigrante para o do anarquista-estrangeiro - seguindose a Segunda República (1930-1937) e da Terceira República (1937-1945), também chamada de "Estado Novo", que finalizou com a abertura democrática pelo Ato Institucional n ${ }^{\circ} 9$ (CARONE, 1991, p. 336). No contexto internacional, o mundo enfrentava a Primeira Guerra Mundial, a crise de 1929 ou "Grande Depressão" e, posteriormente, a Segunda Guerra Mundial.
Após a Primeira Guerra Mundial, a maioria dos países progressivamente aumentou as restrições à livre migração anteriormente existente. Inicialmente, da parte dos Estados de imigração e depois também dos de emigração, alguns dos quais chegaram à proibição integral e outros à permissão só para determinados grupos populacionais. Tornaramse difíceis, portanto, tanto os vistos para entrada quanto as permissões de saída (CÔRTES, 1958, p. 113-114).

O Estado Novo, cujas condições para surgimento o antecederam e foram reforçadas pela crise mundial, iniciou com o Golpe de 1937 - que consolidou Getúlio Vargas no cargo de Presidente da República, que já ocupava desde 1930 e somente deixou em 1945 - e consumou o fechamento do Congresso Nacional, a extinção dos partidos políticos, das eleições e das garantias individuais. Segundo Edgard Carone é o período mais complexo, nebuloso e pouco estudado, muito em razão dos ataques, constantes nos livros da época, contra Vargas, que deveria ser clamado por todos como "grande líder", um "herói" (CARONE, 1976, p. 1-4).

Tratou-se de um Estado autoritário, elitista, conservador, hierárquico e mitológico (CARONE, 1976, p. 166171), muito em razão da construção do líder-o "pai dos pobres", dentre outros predicados criados e divulgados pelo Departamento de Imprensa e Propaganda e pelos idealizadores do regime - e 
da autoridade estatal pela propaganda e pela censura. Ao mesmo tempo, era um período de ditadura constitucional, sendo que a Constituição de 1937 reforçou $\mathrm{o}$ autoritarismo do regime, ao dar plenos poderes ao Presidente da República.

No projeto político estado-novista, o liberalismo, que já vinha sendo abandonado a partir da Primeira República - como se verificou em relação ao enrijecimento da política imigratória e à intervenção na produção cafeeira, auxiliando-a mediante a entrada de mão de obra estrangeira -, foi definitivamente abolido. Isso porque não havia mais lugar para a igualdade e para a não intervenção do Estado, já que agora este deveria atuar como verdadeiro coordenador na distribuição da riqueza nacional, e o "homem novo" deveria participar do processo de progresso, da busca do "bem comum" e da manutenção da "ordem pública", o que conduziria às condições necessárias para a manutenção de uma vida digna para todos (OLIVEIRA, 1982, p. 97-99, p. 129-133).

Ainda no início da década de 30 do século XX, ou seja, após a "Grande Depressão" - e com ela a crise do setor cafeeiro, um dos principais incentivadores da vinda de mão de obra exterior -, iniciou-se um projeto nacionalista, que tomou várias dimensões, dentre elas a restrição da entrada do trabalhador estrangeiro, no intuito de proteger o nacional (CARONE, 1976, p. 7-9). Esse projeto, ainda que com opositores, abrangeu " $[. .$.$] riscar auto-$ maticamente o Brasil da lista dos países de imigração", fechando seus portos à corrente imigratória e impulsionando o sentimento de nacionalidade que o Estado tratava de cultivar (CANCELLI, 1993, p. 247).

Paralelamente ao fomento do $\mathrm{na}$ cionalismo, iniciaram-se medidas de nacionalização. Exemplo foi a "lei de nacionalização do trabalho" (Decreto-Lei n. ${ }^{0}$ 19.482), instituída em 1931, determinou que as indústrias contratassem, para 2/3 (dois terços) de empregados nacionais, apenas $1 / 3$ (um terço) de estrangeiros, e foi acompanhada de outras medidas como a nacionalização gradual da propriedade, de empresas, recursos hidroelétricos e comunicações. O objetivo era restringir a iniciativa estrangeira, seja na esfera política ou na econômica, e o resultado foi o aprimoramento do conceito do imigrante como indesejável (CARNEIRO, 1988, p. 158).

Nesse período, concomitantemente à crise no campo, se consolidava a presença de multidões de trabalhadores nas grandes cidades, a redefinição do espaço urbano e o projeto político de um Estado que se autoimpunha a tarefa de promover a inovação moral e política de toda a sociedade. Essa "inovação" ocorria através de novas estratégias de dominação que negava, em sua essência, os princípios políticos do liberalismo clássico - base para a Constituição do Império, como já visto acima -, e os 
que passaram a empregar novas formas de controle social, agora dirigidos, de maneira cada vez mais centralizada, à sociedade como um todo (CANCELLI, 1993, p. 55).

O projeto político do Estado previu a existência de um aparato policial capaz de exercer o controle social, disciplinar o dia a dia dos trabalhadores e da sociedade como um todo e, ainda, negar a individualidade dos homens a partir do estabelecimento de parâmetros comuns de comportamento e sentimento. A sociedade era engajada no projeto através de campanhas cívicas para a construção de um novo país, dentre elas a campanha anticomunista, bem como da delação dos inimigos do regime, evidenciando que o poder já se dissipava, não estando apenas centrado na máquina estatal, e passou ao nível do corpo, se tornando um biopoder. ${ }^{11}$

Nesse projeto totalitário, nacionalista e nacionalizante, que não tolerava a pluralidade, cada vez mais se consolidava a aversão ao estrangeiro e, se em 1907 e 1913 foram dados os primeiros passos para a regulamentação da expulsão de estrangeiros, esta política foi aprimorada e agravada. E, nesse novo período, não era apenas o caráter subversivo - anarquista e comunista que estava associado à figura do imigrante, mas sua conduta de ordem moral era um dos tópicos prediletos da polícia, quando se referia a este elemento de "caráter degenerado", sendo que as teorias como o positivismo, o darwinismo e o evolucionismo, muito influentes na época, eram utilizadas para fundamentar esse tipo de conclusão (CANCELLI, 1993, p. 165; CARNEIRO, 1988, p. 84).

A "eugenia", que surgiu no século XIX como uma nova ciência destinada a aperfeiçoar a raça humana, tornou-se frequente nos discursos acadêmicos e políticos, expressando ideias comuns ao fascismo italiano, como a construção de um povo forte e com o pensamento concentrado no futuro da pátria. Com base nela, visava-se à formação de uma raça homogênea, de um povo integralmente adaptado à realidade social de seu país e preparado para servi-lo. A isso soma-se que a elite dos intelectuais que pregava a necessidade de se "abrasileirar a República" e de se construir uma consciência nacional, através da proteção a homem brasileiro e do progresso material e moral do país. Foi natural,

11 A expressão biopoder designa a introdução da vida e seus mecanismos aos cálculos do poder e conhecimento, pretendendo transformar a vida humana, inclusive pela aplicação desse poder e conhecimento mediante leis (FOUCAULT, 2004, p. 82). Segundo Michel Foucault, esse processo desenvolveu-se mediante o adestramento e a ampliação das aptidões do corpo como máquina e, posteriormente, através da ingerência no corpo como espécie, estando o Estado atento à sua proliferação, sua longevidade, à geração de corpos dóceis, o que caracteriza uma biopolítica da população (FOUCAULT, 1998, p. 127-128). 
portanto, que o controle da imigração se tornasse um dos meios eleitos para se atingir os objetivos mais imediatos (CARNEIRO, 1988, p. 123-124).

Uma política imigratória aberta a todos entraria em choque com esse ideário político de "homogeneizar a população". Assim, o regime ditatorial de Vargas, embasada pelo pensamento de teóricos como Francisco Campos, Azevedo Amaral e Oliveira Vianna, dedicou-se à elaboração de um projeto educacional e de um projeto contra a entrada de estrangeiros, em prol "do abrasileiramento dos núcleos de colonização", enfatizando o aspecto negativo da presença do estrangeiro. Neste contexto, inclusive, aflorou $o$ antissemitismo na esfera política, institucionalizando o discurso acusatório da demonização e animalização do judeu, considerando, inclusive em documentos oficiais, "raça" inassimilável e psiquicamente degenerada e, portanto, indesejável no Brasil (CARNEIRO, 2003, p. 12).

Os imigrantes que já estavam no país deveriam ser assimilados à força, se necessário, inclusive através da língua, de forma a impor valores nacionais brasileiros, substituindo o sentimento de pertencer a outras nacionalidades. Assim, até setembro de 1939, já estava determinado que o ensino fosse conduzido apenas em língua portuguesa; que nos negócios não houvesse qualquer pronunciamento em outra língua; que todos os serviços religiosos deveriam ser conduzidos em português; que não houvesse quaisquer publicações em língua estrangeira, o que provocou uma crise nessa imprensa, sendo que, após a Segunda Guerra Mundial, a imprensa ligada à imigração ressurgiu apenas em parte (SEYFERTH, 1990, p. 72-74).

Por fim, o Decreto-lei n. ${ }^{\circ} 383$, de 18 de abril de 1938 exigiu, para o licenciamento das sociedades, a sua nacionalização (diretoria com dois terços de brasileiros, sendo seu presidente brasileiro) e o parecer da Delegacia Especial de Segurança Política e Social sobre os antecedentes político-sociais dos componentes da Diretoria e da Delegacia de Estrangeiros. Além disso, no mesmo ano, foram enviados batalhões do Exército para as áreas povoadas predominantemente com imigrantes, principalmente os três estados do Sul, de forma a "nacionalizar" uma "população estrangeira" e fazer cumprir as determinações constantes no parágrafo anterior (CANCELLI, 1993, p. 267-270).

Antes mesmo do Estado Novo, a Constituição de 1934 fixou cotas de entrada de imigrantes em $2 \%$ do total de entradas de cada nacionalidade já presente no país entre $1 .^{\circ}$ de janeiro de 1884 e 31 de dezembro de 1933 (art. 121). Tratou-se da definitiva consolidação legislativa da eugenia e do nacionalismo, que já eram postulados imprescindíveis à política imigratória desde o início da década de 30 do século XX. Essa proposta foi encampada por um grupo de parlamentares liderados por Miguel Couto, 
que decidiu formar uma forte corrente de pressão dentro Assembleia Nacional Constituinte, principalmente para opor uma barreira indireta à imigração de asiáticos, considerados "inassimiláveis" (CARNEIRO, 1988, p. 104-159).

Sob a vigência da Constituição de 1934, sobreveio o Congresso Policial de 20 de outubro de 1936, em que um dos principais temas debatidos foi a entrada, permanência e expulsão de estrangeiros. $\mathrm{Na}$ ocasião, foi realizado um convênio secreto entre os agentes policiais, o Ministério das Relações Exteriores e o Ministério do Trabalho e Emprego para a expulsão "de uma vez por todas" dos apátridas e daqueles cujos consulados negassem conceder visto nos passaportes. Estipulou-se, ainda, que o modelo do processo de expulsão, de naturalização, de controle e permanência seria feito de acordo com os procedimentos da polícia do Distrito Federal, de forma a uniformizar o procedimento. Também foram tomadas medidas no sentido de centralizar as informações sobre estrangeiros na sede da polícia civil do Distrito Federal (CANCELLI, 1993, p. 133-134).

O regime de cotas foi mantido pelo art. 151 da Constituição dos Estados Unidos do Brasil, de 10 de novembro de 1937, inspirada nas Cartas fascistas europeias (WOLKMER, 1999, p. 113-114) e outorgada justamente para conter o "estado de emergência" criado, dentre outros fatores, pela "infiltração comunista", conforme enunciava seu preâmbulo. A concentração de poderes nas mãos do Presidente da República também se deu em matéria de mobilidade humana, e ficou consolidada uma política migratória restritiva e protetiva do mercado de trabalho nacional, bem como voltada ao nacionalismo (art. 16, III, 122, XV, "g" e art. 150).

Depois da Constituição de 1937, várias restrições sobrevieram, principalmente de objetivos antissemitas, dentre elas a Circular n. ${ }^{\circ} 1.127$ (secreta), do Ministério das Relações Exteriores, Ministro Mario Pimentel Brandão, de 7 de junho de 1937, que configura a adoção de uma política imigratória restritiva a judeus; e a Circular n. ${ }^{\circ} 1323$ (Secreta) de 1939, Ministério das Relações exteriores, Ministro Osvaldo Aranha, proibindo a concessão de visto temporário a estrangeiros de origem semita (CARNEIRO, 1988, p. 181).

O Decreto-lei n. ${ }^{\circ} 406$, de 4 de maio de 1938, também chamado de "Lei de Imigração", passou a regulamentar a entrada de estrangeiros no território nacional e, com isso, representou uma nova política migratória, voltada à seleção de "boas correntes migratórias", sendo que para estas tinha orientação favorável, ao contrário da orientação para o "estrangeiro indesejável". A partir deste Decreto, houve a centralização do serviço de registro de estrangeiros no Departamento de Imigração, ligado à Polícia do Distrito Federal e dos estados, e ficou mais clara a dicotomia entre as migra- 
ções desejáveis e associadas à política eugenista e os indesejáveis, scalizados e controlados pela polícia (CANCELLI, 1993, p. 107-129). Nesse sentido, constou expressamente no art. $2 .^{\circ}$ que

"O Governo Federal reserva-se o direito de limitar ou suspender, por motivos economicos ou sociais, a entrada de indivíduos de determinadas raças ou origens, ouvido o Conselho de Imigração e Colonizaçãa".

A partir dele, publicamente, estava vedada a entrada de estrangeiros tidos como aleijados e mutilados, inválidos, cegos, surdos-mudos, indigentes, vagabundos, ciganos e congêneres, os que apresentassem afecção nervosa ou mental, doentes de moléstias infectocontagiosas ou lesões orgânicas com insuficiência funcional (art. 1. ${ }^{\circ}$ I a VII). Ademais, além dos estrangeiros indesejáveis, impedia-se também a entrada daqueles de conduta nociva à ordem pública, à segurança nacional ou à estrutura das instituições, e aos condenados em outros países por crimes de natureza política que determinassem sua extradição (art. $1 .^{\circ}, \mathrm{VIII}$ a XI). Desse modo, a imigração dos indesejáveis passou a ser considerada com um problema de segurança nacional- uma questão política - sendo, a partir de 1939, área decisória do Ministério da Justiça e Negócios do Interior.

Com a eclosão da Segunda Guerra Mundial, as medidas restritivas de controle social ficaram ainda mais fortes, e soluções repressivas começaram a ser reforçadas pelo Estado. Em 29 de janeiro de 1942, foi restringida a liberdade de locomoção, através das normas estipuladas pela polícia. E, depois da entrada do Brasil na Guerra com as potencias do Eixo, houve ainda maiores restrições aos japoneses, italianos, alemães e seus descendentes, que estavam proibidos de ingressar no país, salvo expressa autorização do Presidente, ocasião em que suas atividades seriam oficialmente controladas pela Delegacia de Ordem Política e Social. Para os demais países extracontinentais, era exigida, além de passaporte autenticado, certidão negativa de antecedentes dos últimos cinco anos, certificado de não ter conduta nociva à ordem pública, dentre outras exigências. Ademais, se locomoverem no território nacional, os estrangeiros precisavam de "salvo-conduto" e, por fim, também foi determinada a censura à correspondência internacional (8 de dezembro de 1942).

Não bastassem essas medidas, tratados secretos eram firmados na obscuridade, inclusive visando a entrega de pessoas aos países firmatários, o que contribuía para o sentimento de insegurança de toda a sociedade, mas em especial dos estrangeiros em território alheio. Exemplo foi o tratado com a Alemanha, em que constava a troca de conhecimentos contra o comunismo, anarquismo e outras ideologias contrárias ao Estado, e o intercâmbio de material, informações e provas sobre o comunismo, anarquismo 
e outras ideologias contrárias à Nação. Com base neste tratado foram expulsas e entregues para o serviço secreto alemão, entre 1936 e 1937, Olga Prestes, Elisa Ewer e Ana Gerturde Lambrecht (CANCELLI, 1993, p. 186).

O extremismo da repressão ao estrangeiro e a definitiva relação entre segurança nacional e a questão migratória ocorreu com a criação da Seção de Segurança Nacional, em 1939, órgão destinado, entre outras funções, a " [...] sugerir medidas para a boa marcha do serviço de registro de estrangeiros e fiscalizar suas atividades e dos brasileiros naturalizados", reforçando o trabalho da polícia. Um de seus trabalhos foi remeter formulários a 600 municípios para que estes preenchesse com o nome e a qualificação dos estrangeiros que viviam nas respectivas localidades, no intuito de identificar "elementos suspeitos” (CANCELLI, 1993, p. 140).

\section{CONSIDERAÇÕES FINAIS}

Consoante analisado, o período de 1870-1930 marcou o último momento relevante de grande influxo de estrangeiros, movimento esse que tem sido retomado no século XXI, revitalizando o desafio que é a construção de uma nova política migratória, inclusive mediante conferências nacionais, como a Primeira Conferência Nacional sobre Migrações e Refúgio (COMIGRAR), que objetiva debater amplamente a atual política. Para essa construção, no entanto, além das experiências externas, também se faz necessária a rememoração da gênese do pensamento e ação em relação ao fenômeno da imigração no Brasil.

Isso porque, durante o período estudado, o Brasil recebeu cerca de 3,7 milhões de pessoas, fechou suas fronteiras depois da Constituição de 1934, que estabeleceu cotas para o ingresso de imigrantes e, somente em 1945, reabriu a imigração, mas o volume de entradas foi bem inferior aos momentos anteriores.

Nesse interregno, a política imigratória, outrora relacionada à colonização, objeto de propaganda e interesse governamental devido à necessidade de povoar o território e substituir o trabalho escravo, em períodos autoritários como do Estado Novo se direcionou à repressão do "inimigo externo", como sendo o contraponto da própria formação da nacionalidade brasileira, descrita como uma contraposição ao passado colonial e à submissão a "estrangeiro", e do próprio brasileiro como sendo o "homem novo", capaz de levar seu país ao progresso, independentemente da nominação e do auxílio externo.

O desafio atual, além do convívio com uma herança autoritária e com a incompletude das transições democráticas - gerando um legado autoritário que sobrevive até momento atual, como é a própria Lei n. ${ }^{\circ} 6815$, de 1980, o atual Estatuto do Estrangeiro -, é justamente a 
superação de preconceitos também relacionados à construção de um "inimigo externo". Esse inimigo, na atualidade, não é mais o anarquista, ou o comunista, mas a desigualdade social e a carência de alteridade, como evidenciou o preconceito com a imigração haitiana e senegalesa no início do século XXI.

\section{REFERÊNCIAS}

BARRACLOUGH, Geoffrey. Introdução à História Contemporânea. Trad. Álvaro Cabral. 5. ed. Zahar: Rio de Janeiro, 1983.

BONFÁ, Rogério Luis Giampietro. "Com lei ou sem lei": as expulsões de estrangeiros na Primeira República. Cad. AEL, v.14, n.26, 2009 Disponível em: $<$ http://segall.ifch. unicamp.br/publicacoes_ael/index. php/cadernos_ael/article/viewFile/50/51>. Acesso em: 23 jun. 2013.

CANCELLI, Elisabeth. $O$ mundo da violência: a polícia na Era Vargas. Brasília: EUNB, 1993.

CARNEIRO, Maria Luiza Tucci. O anti-semitismo na Era Vargas: fantasmas de uma geração (1930-1945). São Paulo: Brasiliense, 1988.

. O Veneno da Serpente: reflexões sobre o anti-semitismo no Brasil. São Paulo: Perspectiva, 2003

CARONE, Edgard. Brasil: anos de crise (1930-1945). São Paulo: Ática, 1991.

. Edgard. O Estado Novo (19371945). Rio de Janeiro/ São Paulo: DIFEL, 1976.
CÔRTES, Geraldo de Menezes. Migração e colonização no Brasil. Livraria José Olympio Editora: Rio de Janeiro, 1958.

FELMANAS, Arnoldo. Sua Excelência ... meio-cidadão. Cupolo: São Paulo, 1974.

FOUCAULT, Michel. História da sexualidade I - A vontade de saber. Trad. Maria Theresa da Costa Albuquerque e J.A. Guilhon Alburque. Rio de Janeiro: Graal, 1998. . Microfisica do Poder. Org. e trad. Roberto Machado. Rio de Janeiro: Graal, 2006.

. Right of Death and Power Over Life. In: SCHEPER-HUGUES, Nancy; BOURGOIS, Philippe (Org.). Violence in War and Peace: an anthology. Oxford: Blackwell, 2004.

. Vigiar e punir: nascimento da prisão. Trad. Raquel Ramalhete. 26. ed. Petrópolis: Vozes, 2002.

GAUER, Ruth Maria Chittó. Constituição e Cidadania. Porto Alegre: Livraria do Advogado, 2014.

GORDO, Adolpho. A expulsão de estrangeiros: discursos pronuncia- 
dos na Câmara dos Deputados, nas sessões de 29 de novembro e de 14 de dezembro de 1912. São Paulo: Espindola, 1913.

GUERRA, Maria Pia dos Santos Lima. Anarquistas, trabalhadores, estrangeiros: a expulsão na Primeira República. Dissertação (Mestrado). Faculdade de Direito da UNB. Brasília, 2012.

IOTTI, Luiza Horn. A política imigratória brasileira e sua legislação - 18221914. In: Brasil no Sul: cruzando fronteiras entre o regional e o nacional. Anais do X Encontro Estadual de História. Santa Maria: 10 de julho de 2010. Disponível em: $<$ http://www. eeh2010.anpuh-rs.org.br/resources/ anais/9/1273883716_ARQUIVO_ OBRASILEAIMIGRACAO.pdf $>$. Acesso em: 2 abr. 2014.

OLIVEIRA, Lúcia Lippi. A questão nacional na Primeira República. São Paulo: Brasiliense, 1990.

OLIVEIRA, Lúcia Lippi; VELLOSO, Mônica Pimenta; GOMES, Ângela Maria Castro. Estado Novo: Ideologia e Poder. Rio de Janeiro: Zahar, 1982.

OLIVEIRA, Lúcia Lippi. Nós e eles: relações culturais entre brasileiros e imigrantes. Rio de Janeiro: FGV, 2006.

PETRONE, Maria Thereza Schorer. $O$ imigrante e a pequena propriedade (1824-1930). São Paulo: Braziliense, 1982.
PRADO Jr., Caio. Formação do Brasil Contemporâneo: Colônia. São Paulo: Brasiliense; Publifolha, 2000.

RAMOS, André de Carvalho. Direito dos estrangeiros no Brasil: a imigração, Direito de Ingresso e os Direitos dos Estrangeiros em situação irregular. In: Igualdade, Diferença e Direitos Humanos. Rio de Janeiro: Lumen Juris, 2008.

SEIXAS, Jacy Alves de. Ação direta, greves, sabotagem e boicote: violência operária ou pedagogia revolucionária? p. 127-154. In: CANCELLI, Elizabeth (org.). Histórias de violência, crime e lei no Brasil. Brasília: UNB, 2004.

SEYFERTH, Giralda. Imigração e cultura no Brasil. Brasília: UNB, 1990.

SICILIANO, André L., Antes de discutir a Politica Migratória brasileira: um ensaio conceitual. Universidade de São Paulo: Instituto de Relações Internacionais, 2012.

VENTURA, Deisy; ILLES, Paulo. Qual a política migratória do Brasil? In: Le monde diplomatique Brasil. 7 mar. 2013. Disponível em: <http:// www.diplomatique.org.br/artigo. php?id=1121 $>$. Acesso em: 03 out. 2013.

VIANNA, Oliveira. Populações Meridionais do Brasil: história, Organismo e Psicologia, 5. ed. Rio de Janeiro, José Olympio, 1952.

WOLKMER, Antônio Carlos. História do Direito no Brasil. 2. ed. Rio de Janeiro: Forense, 1999. 